\title{
Development of Basic Education Literacy Profile of Children Who Are Not Going to School in District Rawalpindi, Pakistan
}

\author{
Tahseen Asif, Nazia Rafiq, Muhammad Iqbal, Anwar Ali, Muhammad Asif Haider, \\ Zaib U Nisa, and Hasnain Raza
}

\section{ABSTRACT}

Education is the basic tool to eradicating poverty. Almost half of the population of Pakistan is illiterate and many children who are school aged are not attending the school. Rural areas of Pakistan are considered educationally deprived areas, where particularly girls are not sent to school. Pakistan expends around $2 \%$ of GDP on education that shows the low priority is given to education that is lowest among all developing countries. Even these insufficient resources are not utilized proficiently, due to it the learning standard and learning outcome of the students are below average. The study aimed to find out the causes of educational deprivation among out of school children. This study and data show that about Pakistan's school going population and importance about those children who are not going to school. Quantitative research method was used as methodology. The intended study was descriptive survey in nature. School Heads of Primary and Middle Schools of three tehsils (Rawalpindi, Kahuta, and Murree) were the population of the study and 345 were sampled through multistage sampling technique. Questionnaire used as tool for data collection. The quantitative data analysed through central tendency and standard deviation. The beneficiaries of the study were the students, parents. Educational planners and policy makers, school heads and society. The overall study indicated poor academic performance at early stages of schooling, poverty, teachers' personality, and training, child labour and school management.

Keywords: Deprivation, Poverty, Children not going to school.

\section{INTRODUCTION}

Education is the fundamental right of every human being. It provides the basis for healthy, prosperous, peaceful, and stable world. Education develops the individual's personality, transmits the traditional rules and values, the wisdom of ancestors, and promotes the understanding of modern world and technology. It is an appropriate tool for eradicating poverty. Education is considered a source to decimate poverty. [1], in this regard primary education is considered important [2], [3].

Poverty, or low income, unfairly impact on the both quantity and quality of education at the vast scale, country, level [4], the full scale, area, and school levels [5]-[7] and
Published Online: July 07, 2021

ISSN: $2736-4534$

DOI : $10.24018 /$ ejedu.2021.2.3.128

Tahseen Asif

Department of Ideological and Political

Education, Shanghai University, Shanghai,

Shanghai Province, China.

(e-mail: tahseenasif97@gmail.com)

Nazia Rafiq

Lecturer/Deputy Registrar, Pir Mehr Ali

Shah, Arid Agriculture University,

Rawalpindi, Pakistan.

(e-mail: naziarafiq@uaar.edu.pk)

Muhammad Iqbal

Assistant Professor Department of

Education, Mohi ud Din Islamic University

Nerian Sharif AJ\&K, Pakistan.

(e-mail: iqbal.naeem2010@gmail.com)

Anwar Ali

Department of Epidemiology and Health

Statistics, Xiangya School of Public

Health, Central South University,

Changsha, Hunan, China.

(e-mail: 206908003@ csu.edu.cn)

Muhammad Asif Haider

Beaconhouse school system, Potohar

Campus, Islamabad, Pakistan.

(e-mail: m.asif.haider@bh.edu.pk)

Zaib U Nisa

Hazara University KPK, Pakistan.

(e-mail: nisa.rasheed17@gmail.com)

Hasnain Raza*

Department of Social Sciences, Yangzhou

University, Yangzhou, Jiangsu, China.

(e-mail: razahassnain07@ gmail.com)

*Corresponding Author

the scaled down scale, family level [8]. Many educational researches show that education hardship is made not just by destitution, yet rather similarly by related elements [9]. The percentage of children that did not go to school is most elevated in the least wage quintile. Half of 5 and 18 year olds (and $63 \%$ of females) in the most minimal wage quintile had not gone to school, contrasted with $38 \%$ of the equal stage bunch (and $47 \%$ of females) in the most elevated salary quintile [10]. [11] Likewise information show that poorest families have the most $(46 \%)$ children did not go to school.

Females from poor family's units in rural ranges are few in numbers who attend school and "endure a triple disservice, with their destitution and rural area constituting 
the gender based burden knowledgeable by their good citizen companions" [12]. Information taken from the Pakistan Living Standards Measurement [13] on gender enrolments demonstrates that the gender crevice in enrolment has held on after some time. Be that as it may, increments in young girls' middle school enrolments in 2007, proceeding with onto expanded optional enrolments; demonstrate the impact of policies focused to enhance young girls' enrolment.

An evaluation of World Bank [14] underlined the connections of absence education, non-attendance health offices, non-attendance of accessibility to different administrations, long family, skewed example of area possession, and so forth, with destitution in Pakistan and assessed the primary enrolment rate is $69 \%$. As indicated by Preece [15] it is important to investigate the relations of education for the right knowing of destitution. Nasir and Nazli [16] distinguished an immediate negative relationship between the educational accomplishments and level of prosperity. They inferred that education could help in increasing income potentials of poor people and they turn out to be more gainful.

Child labor is a major problem in Pakistan which has been broadly talked now a day and is as yet being examined in third world countries and in addition in developed countries. Child labour might be characterized as all-time of employment of a man less than 16 years old at a pay rate lower than the current pay rate in the work market. Guiltless little children, who ought to be at schools or play in the ground of the school, are on the way of acquiring their own and their families 'livings. Weiner and Noman [17] assessed education and child labour policies in India and Pakistan. As per their investigation, India and Pakistan have far away among the rest of Asian nations because of their weak policies implementation procedures and not in light of their destitution. Hussain [18] led a survey on children work in Lahore and assessed that around 14 million kids between 5 to 15 years old are involved in child labour in Pakistan.

Cigno et al. [19] is of the viewpoint that the similarity of the globally surge in the child labour. The parents' choices that a youngster goes to job earn money or go to school entirely rely on the cost and advantages of education. Zarif, Nisa, Ahmed, and Mirza [20] investigated in their study that all parent shared their view that they were not literate and were for the most part uneducated. They likewise conceded that their salary was too low, and they were not able to stand to guide their children go to schools. Most importantly, none of the guardians knew about the privileges of their children and demanded that the standard of education and the environment of school was not right for their children. Significantly all the more along these lines, the large family with great number of children was such that more working hands were required to make a decent living. Accordingly, the children were sent to work.

Rena [21] indicates that gender dissimilarity in education brings up numerous issues for governments and for societies. There are numerous elements that add to both male and female crevice in education. Filmer [22] analyses how wealth and gender connect to create inside nation imbalances in education enrolment and accomplishment. The writer highlights that the females are at large level educationally deprived specifically locales of South Asia and North, Western, and Central Africa. Sihotra [23] is of the perspective that education and knowledge is the maximum imperative tool for human self-improvement. Education of young females, in this manner, possesses top need amongst different measures taken to enhance the status of young girl. Subranhmanin [24] prescribes that execution of the policies related to gender disparity needs to move beyond focus on females and young girls to contemplating the linkages between various sub-parts of education and improving measures of advancement that move beyond Quantitative results were found in different places.

Family clash is another home environment dangerous element, which incorporates difference of opinion, quarrel, violence divorce, and separation. In this situation, the child did not go to school as an immediate consequence of any of these circumstances. On the other hand, they may fall behind in their studies due to their circumstance, which then makes them keep away from school [25]. Absence from school reduces a student's capacity to promoted to the next class and the chances for students falling out is largely high [26].

There are number of economic, demographic, and educational reasons of dropouts. One pattern is financial: as the United States economy moves toward a higher-talented work power, secondary school dropouts will have a much harder time surviving financially. A second pattern is demographic: the quantity of students who are by and large at more serious danger that student fail they belong poor and low-wage families, racial, ethnic, and semantic minority are expanding in the schools. The third pattern is the developing push for responsibility in the government funded schools that has delivered method to end social advancement and to establishment secondary school exit exams, both of which could build the number of children who reject to finish secondary school [27].

Factual studies have found that there are less chances of drop out of those children, whose guardians screen and control their activities, give emotional back up, encourage their decision taken by themselves and importantly take interest in their studies and academics [28]. It is normally realized that schools apply impressive impact on the participation rate, continuation of the study and performance of the student.

A few studies demonstrate that financial aspects effects school failure rates with student instructor proportion having a positive and noteworthy impact on secondary school and middle school failure rates. Different areas of teaching learning are likewise connected to dropping out-the poor teaching methodologies become the reason of low motivation, low understanding, and finally leads to drop out. Along these lines, when the instructors do not come prepared into the class for lesson, do not have outlined the work of scheme, improperly check the notebooks, do not check the notebook on regular basis so the learning does not occur [12]. These useless classroom activities have an unfavourable impact on the retention of students.

Researches have demonstrated that early school leaving at the senior level is the result of a long procedure of disengagement of pupils with quantifiable indicators that exist in the early level of schooling. These studies explored 
that academic performance and achievement at primary level and engagement like presence in the class, misconduct in primary and middle school, anticipated removal from secondary school. However, the key elements of pupils' engagement incorporate contribution of students, distinguishing proof and scholastic performance and so forth. Finn [29]. Boyle et al [30] propose that corporal punishment and terrorizing 'influence students' inspiration to go to school'. A few studies show that poor academic performance leads to dropping out. Non-attendance from school and pupil discipline issues are additionally solid indicators of falling, particularly at the secondary level of education.

To find out the causal factors of deprivation of education among children aged 5 to 14 in District Rawalpindi.This study show and finding the beneficial for the participant as schools heads in understanding the reduction of educational deprivation among children. Moreover, study would be supportive in identifying out of school children major causes that create hindrance in the way of schooling Additionally, the study would also be useful for out of school children, their parents, teachers, administrative staff of the government and non-government organizations, policy makers and planners and the society as well.

\section{Methodology}

This study composed to develop basic education literacy profile of out of school children in District Rawalpindi. The researcher used quantitative approach as methodology. Researcher utilized quantitative analysis as descriptive survey to explore the causal factors of educational deprivation. The population of this study was comprised of 1546 schools' head of primary and middle Schools of district Rawalpindi. There was total 697 school's head from primary and middle boys' schools and 849 school's head from primary and middle girls' schools. There are seven tehsils in Rawalpindi district. Three tehsils (Rawalpindi, Murree, and Kahuta) out of seven were selected in final study. The sample consisted of 345 primary and middle schools among which 230 were primary male and female schools and 115 were middle male and female schools and they were selected through multistage sampling technique. In this study, questionnaire used to collect data associate to the research objective. Purpose of this questionnaire was to find out causal factors of deprivation of education among children. The responses were collected personally by visiting to the concerned schools. Researcher conducted survey personally in systematic and structured manner.

After collecting data, responses of the sampled respondents were systematically organized, analyzed, and measured; and results were drawn through Statistical Packages for Social Sciences (SPSS). Descriptive statistical techniques (percentage, mean and standard deviation) were used to generate results.

\section{RESUlTS AND DISCUSSION}

Find out the causal factors of educational deprivation among school aged children's different indicators were used in questionnaire. The Table I and II below show the mean score of each domain or indicator that was analyzed from the reported responses of schools' head.

TABLE I: FACTORS CONTRIBUTING IN EDUCATIONAL DEPRIVATION AT

\begin{tabular}{ccc}
\multicolumn{3}{c}{ LARGE SCALE } \\
\hline S. No & Domains & Mean Scores \\
\hline 1 & Poverty or financial constraints & 3.40 \\
2 & Child Labour & 3.59 \\
3 & Parents' awareness and Children's & 3.18 \\
4 & interest & 3.62 \\
5 & Disability & 2.88 \\
6 & Teacher's personality and availability & 3.82 \\
7 & Government assistance and reforms & 3.81 \\
8 & Migration & 3.62 \\
9 & Access & 3.75 \\
10 & Poor Academic Performance & 3.88 \\
11 & School environment and & 3.48 \\
\hline
\end{tabular}

The analysis of the table No 1 showed that poor academic performance at early stages, teacher's personality, government assistance and reforms, migration, access, disability, child labour and poverty were contributing at large scale in educational deprivation. Majority of the respondents accepted that these factors were affecting child education badly in Rawalpindi district.

\begin{tabular}{ccc} 
TABLE II: FACTORS, LESS CONTRIBUTING IN EDUCATIONAL DEPRIVATION \\
S. No & Domains & Mean Score \\
\hline 12 & Gender Disparity & 3.10 \\
13 & Medium of instruction & 2.1 \\
14 & Ethnicity & 2.54 \\
\hline
\end{tabular}

The analysis of Table II showed that majority of the respondent rejected the above mentioned factors. Girls are encouraged to send to school even in the rural areas of Rawalpindi, while parents prefer English language as medium of instruction instead of national or regional language.

The findings of the study uncover that there are several causes of deprivation of education among children. Poor academic performance at early stages causes dropout at secondary level is found major cause of educational deprivation. These findings were consistent with the conclusion from [31] studies which identified that weak academic background of the pupils is the obstacle in the way of future studies.

The study uncovered that Government assistance in the form of stipend and scholarship and proper implementation of educational reforms may find helpful in reducing high number of out of school children as well as dropouts. According to the conclusion of [32] that supported the study, policy regarding primary education is ignored and have not implemented in a good way. Discontinuity in democratic governments leads to unimplemented education policies. Governments formulate policy but there is lack of strong implementation mechanism. Another factor that contributes a lot is teacher's personality, training, and availability. Teacher compels students to take interest in study and attend school regularly. For this purpose, teacher should be well-trained because parents prefer trained and skilful teacher when sending their children to school. Parents keep concern about the availability of sufficient 
number of teaching staff which ultimately reflects in dropouts. Similar results were seen in the findings of [33] that the major cause of dropout is careless, naive, and irresponsible teacher that uses passive teaching methods at primary level.

The findings of the study establish fact that access to school, migration, and disability become the reason of educational deprivation at large scale. It is discoursed in the study that children who live in hilly area have to walk one or two hours to reach at school, people have to migrate due to work and seasonal changes that disconnects children education. It is discovered in the study that children feel reluctant to attend school if they have any disability.

There is a strong link between poverty and child labor. Parents give priority to income generation instead sending their children to school. Poor parents force their children to stay at home and work for family, while employment opportunities attract children to work too. Illiterate parents were seemed less aware to the importance of education while students do not consider education important for their future life. These findings were consistent from the conclusions of [34]-[36] studies that revealed poor parents do not any interest that their children go to school, and they force them to earn. Children have no other choice except to work. They are obliged to share financial load. Finally, it is found that poverty, socio economic and child labour factors were major causes of educational deprivation.

The finding of the study explored that less gender discrimination is seen in Rawalpindi district. Parents encourage girls to send school even in rural areas of the district. There were no early marriages done in the district but at some extent parents prefer boys to send school over girls, but overall gender disparity was not contributing enough in educational deprivation. However, the findings of the study were quite contrary to the conclusions of the study findings of [36] their findings revealed that usually gender disparity is seen at primary level. One of the reasons of high dropout rate is that parents avoid sending girls to school as they consider educating girl is wastage of money whereas boys are preferred as it seems good investment. Boys will earn and give their contribution in releasing economic burden.

The finding of the study uncovers that efficient management of school and its comfortable environment promote education, while corporal punishment, medium of instruction and ethnicity are not the major factors that increasing the number of out of school children. Even parents want their children get education in English language instead of national or regional language.

\section{CONCLUSION}

Poor academic performance of children at early stages of education, poverty, child labour, and access to school, disability, migration, government assistance, and teacher's personality were found major causes of educational deprivation in district Rawalpindi. Gender disparity, ethnicity and medium of instruction were found less contributing to educational deprivation even girls were encouraged to send school and there was no trend of early marriages was found in the district.

\section{RECOMMENDATIONS}

Keeping in view the findings and conclusions, following recommendations are described:

Poor academic performance of children at early stages of education are linked with multiple issues, district government may take necessary steps to counter these problems with collaboration of provincial government and UN agencies for effective outcome.

Gender disparity, early marriages, ethnicity, and medium of instruction were found less contributing to educational deprivation, so by effective media campaign regarding promoting awareness among people may uproot them completely.

\section{ACKNOWLEDGMENT}

Authors pay thanks to concerned universities and department for providing free access to data bases.

\section{CONFLICT OF INTEREST}

Authors declare no conflict of interest.

\section{REFERENCES}

[1] Hussain, A. (1988). Strategic issues in Pakistan's economic policy. Progressive Publishers.

[2] ASER. 2013. Annual status of education report: ASER-Pakistan 2012. Lahore, Pakistan.

[3] Becker, G. S. (2009). Human capital: A theoretical and empirical analysis, with special reference to education. University of Chicago press.

[4] Boyle, S., Brock, A., Mace, J., \& Sibbons, M. (2002). Reaching the Poor: The'costs' of sending children to school: a six country comparative study, synthesis report (No. 666-2016-45490).

[5] Cigno, A., Rosati, F. C., \& Guarcello, L. (2002). Does globalization increase child labor?. World Development, 30(9), 1579-1589.

[6] DeSocio, J., VanCura, M., Nelson, L. A., Hewitt, G., Kitzman, H., \& Cole, R. (2007). Engaging truant adolescents: Results from a multifaceted intervention pilot. Preventing School Failure: Alternative Education for Children and Youth, 51(3), 3-9.

[7] Rose, P. M., \& Dyer, C. (2008). Chronic poverty and education: a review of literature. Chronic Poverty Research Centre Working Paper, (131).

[8] Filmer, D. (2005). Gender and wealth disparities in schooling: Evidence from 44 countries. International Journal of Educational Research, 43(6), 351-369.

[9] Finn, J.D. 1993. School Engagement \& Students at Risk. Washington DC: National Center for Education Statistics.

[10] Govinda, R. 2002. India Education Report, New Delhi. Oxford University Press.

[11] Harper, C., Marcus, R., \& Moore, K. (2003). Enduring poverty and the conditions of childhood: lifecourse and intergenerational poverty transmissions. World development, 31(3), 535-554.

[12] Heubert, J. P., \& Hauser, R. M. (1999). High stakes: Testing for tracking, promotion and retention. Washington, DC: National Academies Press. Retrieved January, 17, 2003.

[13] Jimenez, E. (1995). Human and physical infrastructure: Public investment and pricing policies in developing countries. Handbook of development economics, 3, 2773-2843.

[14] Lipton, M., \& Ravallion, M. (1995). Poverty and policy. Handbook of development economics, 3, 2551-2657.

[15] Lloyd, C., Mete, C., \& Grant, M. (2007). 4 Rural girls in Pakistan Constraints of policy and culture.

[16] Michaelowa, K. (2001). Primary education quality in francophone Sub-Saharan Africa: Determinants of learning achievement and efficiency considerations. World Development, 29(10), 1699-1716.

[17] Nasir, Z. M., \& Nazli, H. (2010). Education and earnings in Pakistan. Working Papers \& Research Reports, RR-No.

[18] Pakistan Bureau of Statistics. 2010. Pakistan social and living standards measurement survey 2010-11. Islamabad, Pakistan. 
[19] Pandy, A. P. 2002. Gender Disparity in Education-Needs Community Participation. Paper presented at the 25th Annual Conference of the Indian Association for the Study of Population Sciences, Mumbai India.

[20] Preece, J. (2006). Widening participation for social justice: poverty and access to education. In widening access to education as social justice (pp. 113-126). Springer, Dordrecht.

[21] Reid, K. 1999. Truancy and schools. New York: Routledge.

[22] Rena, R. 2005. Gender Inequality in Education-An Eritrean Perspective. The Global Child General, 2, 43-45.

[23] Rumberger, R. W. (1995). Dropping out of middle school: A multilevel analysis of students and schools. American educational Research journal, 32(3), 583-625.

[24] Subranhmanin, R. 2006. Main Streaming Gender for Better Girl's Education: Policy and Institutional Issues. Available at: www.ungei.org/resources/files/unicef issue4 mainstreaming gender.pdf.

[25] UN Millennium Project. 2005. Towards universal primary education: investments, incentives and institutions, London: Earth scan.

[26] Watkins, K. 2000. Oxfam Education Report, Oxford. Oxford University Press.

[27] Weiner, M., \& Noman, O. (1995). The child and the state in India and Pakistan.

[28] World Bank. 2001. Poverty in Pakistan in the 1990s: An interim assessment report. Pakistan Human Development Forum, Islamabad.
[29] Zarif, T., \& Aziz-un-Nisa, A. A. (2013). Understanding reasons of child labour in a developing economy: A qualitative study of Karachi, Pakistan. Asian Journal of Social Sciences \& Humanities, 2(2), 388393.

[30] Boyle, S., Brock, A., Mace, J., \& Sibbons, M. (2002). Reaching the Poor: The'costs' of sending children to school: a six country comparative study, synthesis report (No. 666-2016-45490).

[31] Gul, R., \& Arshad, A. (2013). Causes of Dropout Rate in Government High Schools (Male). American international journal of research in humanities, arts and social sciences, 3(1), 120-125.

[32] Imtiaz. S. 2014. Factors of drop out at primary schools level: case studies from the Islamic Republic of Pakistan. University of Nordland.

[33] Hussain, A. H., Khattak, N. U. R. K., Khan, A. Q. K., Bangash, S. B. $\&$ Nazir, N. N. (2010). An Assessment of the Causes of Drop outs in Primary Schools of Mountainous Areas of District Swat.

[34] Zarif, T., \& Aziz-un-Nisa, A. A. (2013). Understanding reasons of child labour in a developing economy: A qualitative study of Karachi, Pakistan. Asian Journal of Social Sciences \& Humanities, 2(2), 388393.

[35] Ali, K., \& Hamid, A. (1999). Major determinants of female child labour in urban Multan (Punjab-Pakistan).

[36] Khan, G. A., Azhar, M., \& Shah, S. A. (2011). Causes of primary school dropout among rural girls in Pakistan. 